\title{
Prediction of the Catalyst Attrition Rate in an Industrial Fluid Catalytic Cracking Operation
}

\author{
Okwonna Obumneme O., Otaraku Ipeghan J., Oduola Koyejo M.
}

\begin{abstract}
Attrition occurs due to particle motion and inter-particle collision and therefore is a major source of catalyst deactivation in fluid catalytic cracking (FCC) processes which results in loss of valuable catalyst materials, reduced process efficiency, and equally affects production. This work aims at predicting the attrition rate of a commercial catalyst used for industrial FCC operation. Design and operation data were used to carry out technical evaluation, physicochemical property test analysis, and modeling. Results show that mechanical stress rather than the thermal stress gave rise to attrition in this unit. The specific attrition rate which was modeled with the exponential decay model had $\mathbf{R}^{2}$ value of 0.999, Standard Error of $\mathbf{0 . 0 0 0 9 0 8}$ and RSS value of $1.403 * 10$ and therefore adequately modeled this rate. It was assumed that abrasion was solely responsible for attrition in this unit and that attrited particles were lost as microfines and not retained within the unit during operation.
\end{abstract}

Index Terms - FCC Unit, Catalyst Attrition, Rate of attrition, Mathematical Modelling.

\section{INTRODUCTION}

Attrition is a major source of catalyst deactivation in the fluid catalytic cracking (FCC) process. It occurs due to particle motion and inter-particle collision resulting from gas flows and the bed-to-wall impact on the process. Although these collisions are required for the efficient performance and operation of fluidized-bed reactors, the resulting attrition is a major drawback in the operation of these units. The main consequence of catalyst attrition is the generation of fines which eventually pass as dust leading to the loss of valuable catalytic materials [1], [2]. This loss has both operational and economic implications on the running of the FCC units. Loss of catalyst particle fines increases the coarseness of the bed particle size distribution hence the need for addition of makeup catalyst in order to keep the system at a required level of fines [3], [4]. Whereas increased coarseness is undesirable,

Okwonna Obumneme Onyeka, Africa Centre of Excellence for Oilfield Chemicals Research (ACE-CEFOR), University of Port Harcourt, Choba, Nigeria.

Otaraku Ipeghan J, Department of Chemical Engineering, University of Port Harcourt, Choba, Nigeria.

Oduola Koyejo M., Department of Chemical Engineering, University of Port Harcourt, Choba. having large amount of particle fines within the system could give rise to a fluidized bed whose particle size distribution may be too fine to achieve the desired result.

Various models have been used to describe attrition in the FCC unit. Kramp et al [3], Thon et al [5], Hartge et al [6], Tamjid et al [7], Wether and Rappenhagen [8] presented models which predicted catalyst attrition based on their source of occurrence for a Circulating Fluid Bed (CFB) riser, and a cold model fluidized unit, among others. Wether and Hartge [4] considered attrition in modeling a fluid bed reactor whereas Puttmann et al [9] through a population balance simulated the particle size distribution within a reactor in stationary state. Wei et al [2] in describing attrition and its mechanism provided a matrix to describe a laboratory experimental attrition process. Wu et al [10] investigated catalyst attrition using the exponential decay model for a laboratory scale process. These models were either applied or developed based on laboratory scale investigations. It is important to predict attrition process on commercial FCC catalysts used for industrial scale operations. This will address the peculiarities of these units and hence the need for this study. The aim of this work is therefore to predict the rate of attrition on the commercial FCC catalyst for an industrial process and condition.

\section{METHOD}

The method used in this work include: technical evaluation, catalyst characterization, data analysis and mathematical modeling.

\section{A. Technical Evaluation}

Technical evaluation of the design and operation of a selected FCC unit in Nigeria (UOP technology) was done. Data from 5 continuous run operations were used to study the effect of attrition on the commercial grade catalyst under consideration. The catalyst level inside the regenerator during 
operation was evaluated from the pressure exerted by the catalyst at each point in time and recorded on a $6 \mathrm{hr}$ interval while the amount of the makeup catalyst was deducted so as to evaluate the catalyst loss in the process.

\section{B. Catalyst Characterization}

The commercial grade catalyst used in this work consists mainly of Y-zeolite with an Alumina base built on Nickel support. Its length and bulk density were $3-6 \mathrm{~mm}$ and $0.8 \mathrm{~g} / \mathrm{cm}^{3}$ respectively. Other physical and chemical properties which were used to characterize the fresh and spent catalyst include: particle size, total surface area, sodium oxide and rare earth oxide content analysis. The particle size, total surface area and compositional analysis were done using sieves, BET water adsorption method, and X-ray fluorescence (Phillips PW2400) respectively.

\section{Attrition Measurement}

Using the data obtained from the technical evaluation of this FCC process, the rate of catalyst attrition was predicted using the model presented by $\mathrm{Wu}$ et al [1] whereas the parameter estimation was done using Data Fit version (9.0). The rate of attrition on the unit was assessed from the change in mass of the catalyst bed within the regenerator where attrition was assumed to be solely responsible for the catalyst loss within the unit. The catalyst which comprises of various particle size distributions (as shown in Table 3) was considered with the assumption that there was no form of interaction among these particles. Hence, predicting the mass of the full-sized sample implied a linear combination of these fractions with the correlation of Equation 1.

$M=\sum_{i=1}^{n} x_{i} * m_{i}$

(1)

Where:

$\mathrm{M}=$ Mass of catalyst $x_{\tilde{i}}=$ mass fraction of various particle sizes $; m_{i}=$ average mass of particle at time $\mathrm{t} ; \mathrm{n}=$ particle class size

Therefore, the attrition rate is given by Equation 2:

$R=\frac{d M}{d t}=\sum_{i=1}^{n} x_{i} \frac{d M i}{d t}=\sum_{i=1}^{n} x_{i} \leqslant R_{i}$

(2)
The specific attrition rate of the catalyst particles which is a ratio of attrition rate to the change in mass of the catalyst bed as shown in Equation 3

$R_{b}=\frac{R}{M_{0}-M}=\frac{\sum_{i=1}^{n} x_{i^{*}} R_{i}}{M_{0}-\sum_{i=1}^{n} x_{i^{k}}^{n} m_{i}}$

Where:

$R=$ Attrition rate $R_{b}=$ specific attrition rate; $R_{i}=$ attrition rate for particle $i$

Note: $x_{i}$ was obtained from particle size analysis (Table 3), whereas $m$ was determined during the operation (see Section C).

Furthermore, the specific attrition rate was modeled with the exponential decay model of Equation 4 as presented by Wu et al [8].

$R_{b}=R_{c}+D e^{-\frac{1}{\tau}}$

Where: $R_{c}=$ steady-state specific attrition rate; $D=$ total decay value of the specific attrition rate; $\tau=$ decay time parameter

NB: $D$ and $\tau$ were obtained from a least-square nonlinear fit of the technical data.

The initial specific attrition rate (at time $\tau=0$ ) is given by Equation 5

$R_{0}=R_{e}+D$

Also, the percentage error values between the observed and predicted values for the specific attrition rate would be obtained using Equation 6.

Absolute Relative Error $(\%)=$
$\frac{\sum y_{\text {predicted }}-\sum y_{0 b \text { berved }}}{\sum y_{\text {observed }}} * 100$

\section{III.RESULTS AND DISCUSSION}

The results obtained from the technical evaluation, catalyst mass loss, catalyst characterization and attrition study have been presented and discussed as follows:

\section{A. Technical Evaluation}

The observations from the technical evaluation of the FCC unit are shown in Table 1 
Table 1: Design and operating conditions of regenerator

\begin{tabular}{lrrrrrr}
\hline \multicolumn{1}{c}{ Parameter } & \multicolumn{7}{c}{ Operating Condition } \\
& \multicolumn{1}{c}{ Design } & \multicolumn{1}{c}{ Run 1 } & Run 2 & Run 3 & Run 4 & Run 5 \\
\hline Regenerator Dense Bed Temp $\left({ }^{\circ} \mathrm{C}\right)$ & 680 & 681 & 695 & 723 & 716 & 710 \\
Regenerator Pressure $\left(\mathrm{KNm}^{-2}\right)$ & 206.92 & 216.72 & 211.82 & 215.75 & 220.65 & 218.69 \\
Air flowrate $\left(\mathrm{KNm}^{3} / \mathrm{hr}\right)$ & 155.7 & 129.72 & 129.87 & 130.04 & 129.99 & 128.08 \\
Blower air discharge Pressure $\left(\mathrm{KNm}^{-2}\right)$ & 350.09 & 294.2 & 196.13 & 294.2 & 294.2 & 294.2 \\
Air Temperature $\left({ }^{\circ} \mathrm{C}\right)$ & 183.6 & 184 & 176 & 178 & 181 & 179 \\
Air blower speed $(\mathrm{krpm})$ & 5.8 & 6 & 6 & 6 & 6 & 6 \\
\hline
\end{tabular}

NB: average values for the operating data has been provided

Table 1 shows the design and operating condition of the regenerator section of the FCC unit during the period under investigation. Compared to the design values, the catalyst bed temperature of $723{ }^{\circ} \mathrm{C}$ for the $3^{\text {rd }}$ run operation was the highest whereas the $681^{\circ} \mathrm{C}$ for $1^{\text {st }}$ run operation was the least and also that which is closest to the design value of $680{ }^{\circ} \mathrm{C}$. The fluidizing air temperature for the $1^{\text {st }}$ run operation was also the closest to the design value. Also, the regenerator pressure of $220.65 \mathrm{KNm}^{-2}$ for the $4^{\text {th }}$ run operation was the highest within this unit and could have some implications on catalyst attrition.

\section{A. Catalyst loss on the system}

The mass of catalyst within fluid bed was evaluated from the pressure exerted by the catalyst inside the regenerator and monitored from the control unit. The catalyst losses for the $1^{\text {st }}$ and $4^{\text {th }}$ run are shown in Figure 1 whereas plots for the $2^{\text {nd }}, 3^{\text {rd }}$ and $5^{\text {th }}$ run are shown in Figure 2.

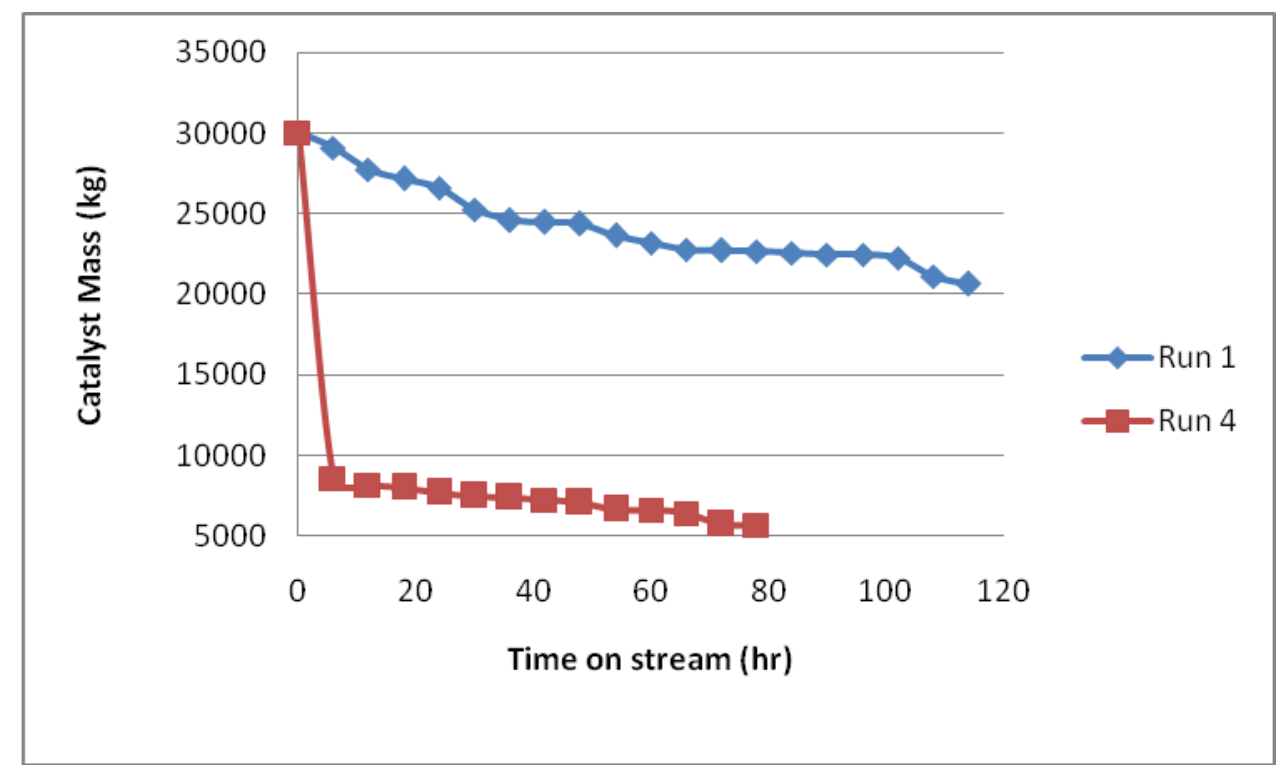

Figure 1: Catalyst Mass Vs Time for Run 1 and 4 


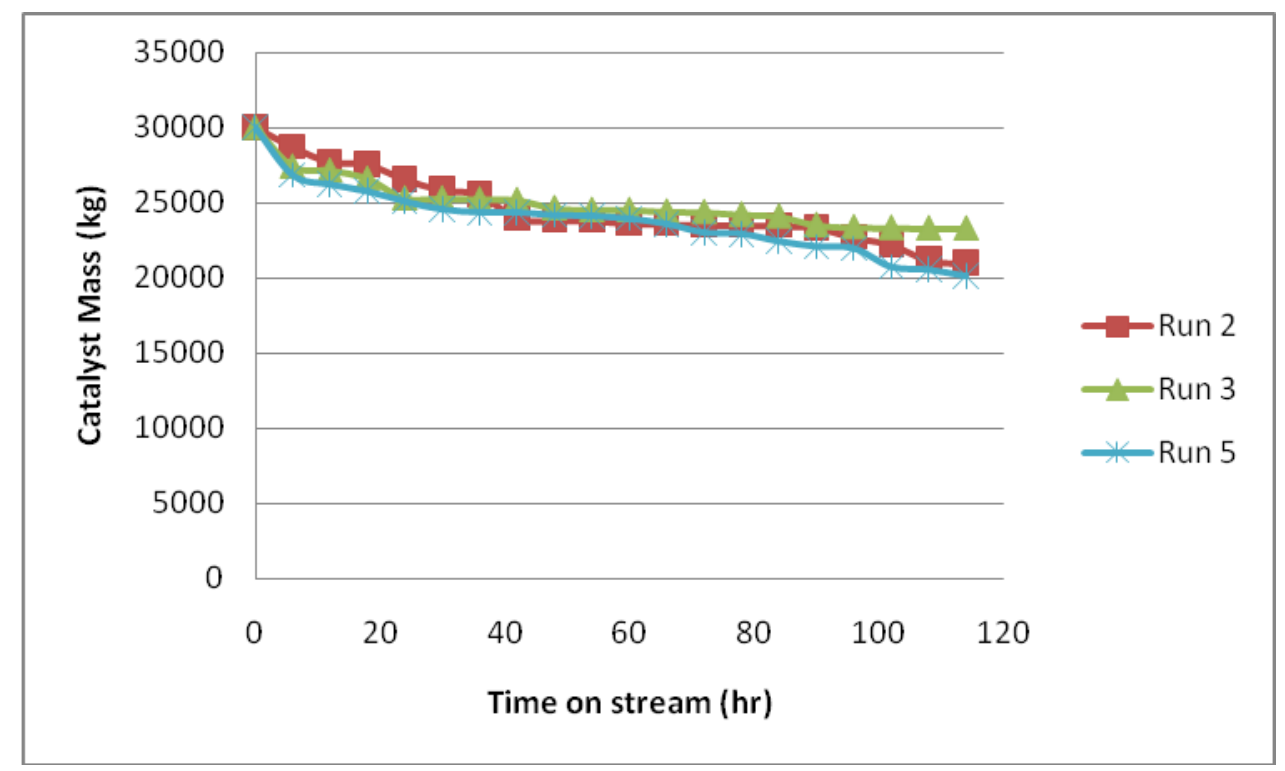

Figure 2: Catalyst Mass Vs Time for Run 2, 3 and 5

Figures 1 and 2 show a general decline in the mass of the catalyst bed inside the regenerator for all the cases considered. In this study the amount of makeup catalyst $\approx 2700 \mathrm{~kg} /$ day (3tons/day) was first deducted. The sharp decline observed in the $4^{\text {th }}$ run could be due to the high pressure of the operation which might have had serious consequence on catalyst loss and the attrition process or could be indicative a technical fault in the unit; although a gradual decline in mass is observed in the $1^{\text {st }}, 2^{\text {nd }}, 3^{\text {rd }}$ and $5^{\text {th }}$ run operations. The gradual decline in the mass of the catalyst implies a steady loss of elutriable fines within this unit which Wu et al [10] had ascribed to characteristic loss of smaller fines in the catalyst bed and according to Kramp et al [3] also leads to increased coarseness of the fluid bed. With continuous removal of the surface layer from the parent material, these coarse particles could undergo further attrition over time [11]. The initial sharp decline could infer the unsteady state process described by $\mathrm{Wu}$ et al [12]. Moreover, whereas increased pressure within the regenerator could be said to have a significant impact on the catalyst loss and attrition process, the same cannot be said of temperature. In other words, mechanical stress rather than thermal stress could be responsible for attrition in this unit; although there is need for further research in this area. Also, considering the performance of this unit in terms of catalyst loss and with respect to design, data from the first run operation have been used to model the attrition rate of the catalyst.

\section{A. Catalyst Characterization}

The catalyst properties such as particle size, surface area, and component analysis were used to characterize the fresh and spent catalysts samples. As stated earlier, the particle size, total surface area and compositional analysis were done using sieves, BET water adsorption method, and $\mathrm{x}$-ray fluorescence respectively and the results presented in Table 2 as shown 
Table 2: Physicochemical property analysis of the catalyst

\begin{tabular}{lll}
\hline Property & Fresh Catalyst & Spent Catalyst \\
\hline Apparent Particle Size $(\mu \mathrm{m})$ & 71 & 75 \\
Total Surface Area $\left(\mathrm{m}^{2} / \mathrm{g}\right)$ & 251 & 118 \\
Rare Earth Oxide $(\mathrm{wt} \%)$ & 1.9 & 1.6 \\
Sodium Oxide $(\mathrm{wt} \%)$ & 0.3 & 0.2 \\
\hline
\end{tabular}

Note: values for the spent catalyst were the average from 5 run operations

Table 2 shows that there were variations in the properties of the fresh and spent catalysts. Increase in the apparent particle size of the catalyst from $71 \mu \mathrm{m}$ for the fresh catalyst to $75 \mu \mathrm{m}$ for the spent catalyst is an evidence of the attrition of the smaller sized particles thereby leading to increased coarseness of the catalyst bed and hence corroborates the work of Kramp et al, (2011). This increase in apparent particle size gave rise to a decrease in the reaction surface area from 251 to $118 \mathrm{~m}^{2} / \mathrm{g}$ and this could have an adverse effect on product yield as suggested by Meyer et al [13] and Fiske [14]. The Rare Earth Oxide and Sodium Oxide decreased from 1.9 and $0.3 \mathrm{wt} \%$ to 1.6 and $0.2 \mathrm{wt} \%$ respectively. These components are essential elements in creating the matrix that binds the catalyst system together. The use of Rare Earth Oxide for zeolite and thermal stability as well as for improving the reaction characteristics of the FCC catalyst has been reported by Vogt and Weckhuysen [15] although these could be lost through attrition because of structural deformation [16], [17].

The mass fraction of the particle size fractions retained on each sieve was obtained and presented in Table 3.

Table 3: Particle size analysis for fresh catalyst and spent catalyst

\begin{tabular}{ccccc}
\hline Particle & Diameter $(\mu \mathrm{m})$ & Nominal Average Diameter $(\mu \mathrm{m})$ & \multicolumn{2}{c}{ Mass fraction $(x)$} \\
& & & Fresh $(\mathrm{wt} \%)$ & 0 \\
Spent $(\mathrm{wt} \%)$ \\
\hline 1 & $0-20$ & - & 2.69 & 1.052 \\
2 & $0-30$ & 25 & 4.54 & 3.97 \\
3 & $0-40$ & 35 & 9.644 & 5.2449 \\
4 & $0-45$ & 43 & 12.05 & 7.34 \\
5 & $0-50$ & 47 & 13.25 & 13.78 \\
6 & $0-60$ & 55 & 16.87 & 25.21 \\
7 & $0-80$ & 70 & 18.079 & 43.41 \\
8 & $0-100$ & 90 & 22.89 & 2 \\
\hline
\end{tabular}

Note: values for the spent catalyst were the average from 5 run operations

Results of Table 3 show that the least sized particles were more attrited than the larger sized particles and therefore provides further proof as to the increased coarseness of the catalyst bed due to attrition in line with the work of Wei et al [2] and this view was corroborated by Sadeghbeigi [18] who also reported an adverse effect of this increased bed coarseness on the fluidization process.

\section{A. Rate of Attrition}

The rate of the attrition of the catalyst particle has been evaluated by employing Equation 2, and the resultant time dependence of this rate is presented in Figure 3. 


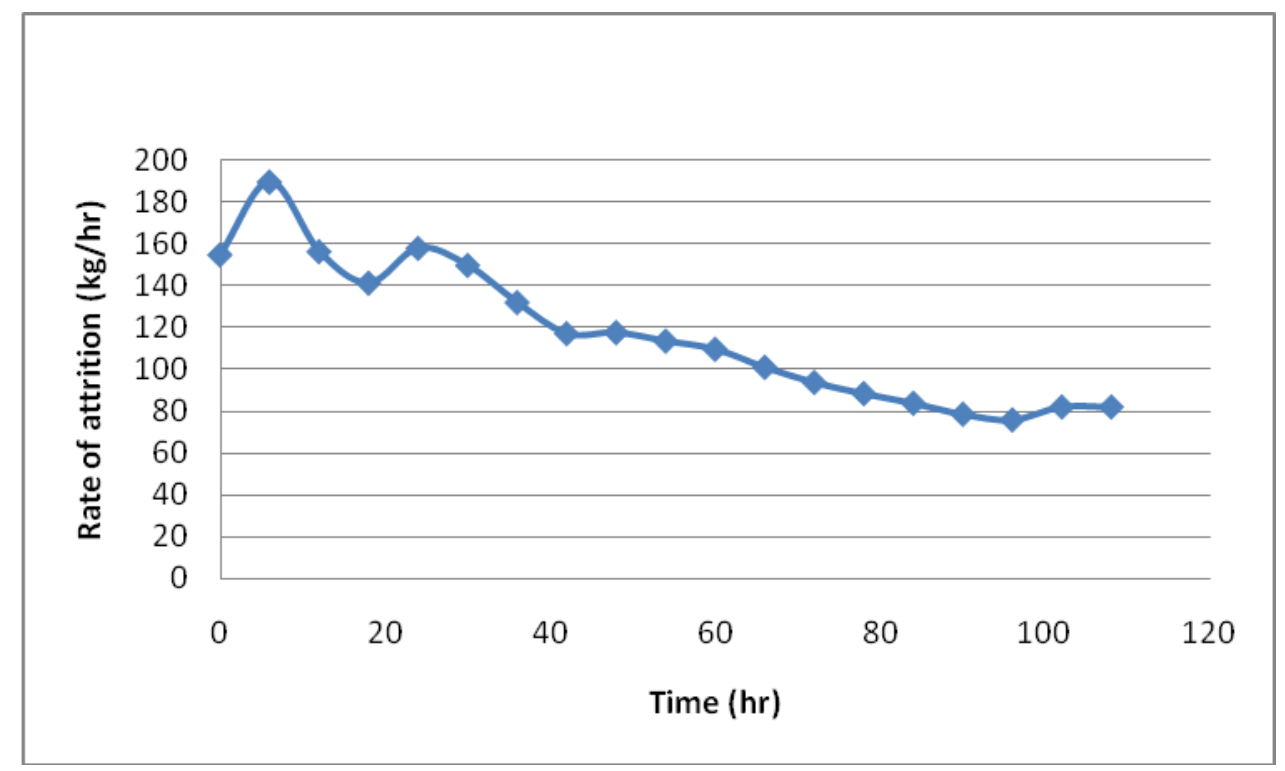

Figure 3: Time dependence of the catalyst attrition rate.

From Figure 3 it can be seen that the rate of attrition on the catalyst increased within the first 6 hours after which a decline was observed. The initial increase could be attributed to early non-steady state stage of attrition as well as the amount of small sized particles contained in the catalyst composition which are easily lost as microfines due to attrition. According to Sadeghbeigi [18], catalyst particles of 0-40 $\mu \mathrm{m}$ size distribution are easily lost at this stage and in addition to the inherent properties of the catalyst; this loss could also be a function of the cyclone efficiency. The non-steady state stage was observed within the first $30 \mathrm{hrs}$ of operation after which steady-state process emerged.

A plot of the specific attrition rate obtained from Equation 3 is shown in Figure 4.

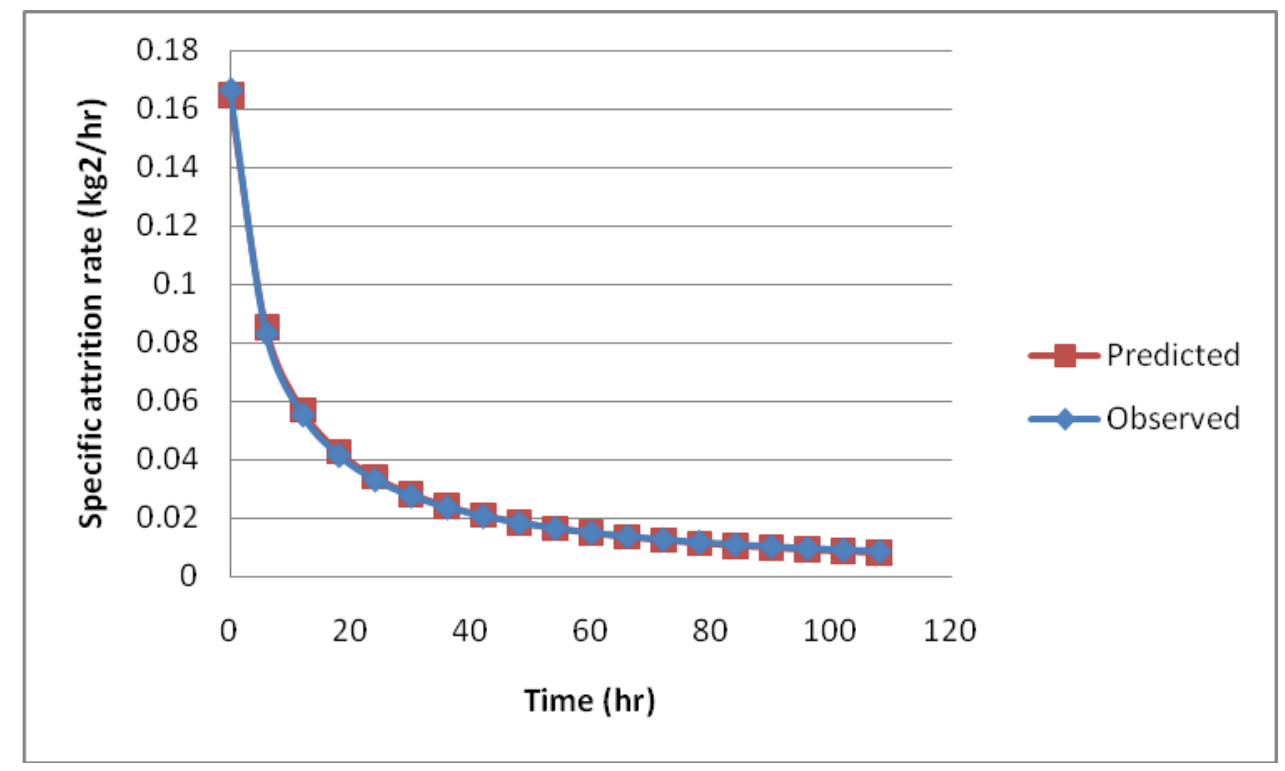

Figure 4: Specific attrition rate vs Time

The specific attrition rate as proposed by $\mathrm{Wu}$ et al [1], is a property used to study attrition behavior of catalysts which describes how the attrition rate changes with continuous change in the mass of the catalyst bed. Figure 4 shows that there was also a sharp decline in this property during the early non-steady-state stage of this process after which the 
decline became gradual and almost constant in the steady-state stage of attrition. The non-linear fitting of the technical data to Equation 4 was used to model the specific attrition rate. The estimated statistical parameters of regression coefficient, standard errors, T-ratio, residual sum, and residual average were also determined.

Table 4: Parameter estimates for the prediction of specific attrition rate of FCC catalyst

\begin{tabular}{rrrrrrrr}
\hline $\mathbf{R}_{\mathbf{c}}\left(\mathbf{k g}^{\mathbf{2}} / \mathbf{h r}\right)$ & $\mathbf{D}$ & $\mathbf{R}_{\mathbf{0}}\left(\mathbf{k g}^{\mathbf{2}} \mathbf{h r}\right)$ & $\mathbf{R}^{\mathbf{2}}$ & Standard Error & Residual Sum & Residual Average & $\mathbf{R S S}$ \\
\hline 1.08115 & -1.08251 & -0.00136 & 0.9994 & 0.000908 & $-1.77983 \mathrm{E}-15$ & $-9.36751 \mathrm{E}-17$ & $1.40304 \mathrm{E}-05$ \\
$(0.0059)$ & $(0.0061)$ & & & & & & \\
$182.1219^{\#}$ & $-176.9888^{\#}$ & & & & & &
\end{tabular}

NB: ()$=$ Standard Errors; $\#$ = t-value

Hence for the attrition time considered, the modeled equation predicting the specific attrition rate on this unit is as shown in Equation 7:

$$
R_{b}=1.08115-1.08251 e^{-\frac{1}{t}}
$$

Where: $\mathrm{t}$ is the attrition time $(\mathrm{h})$.

Table 4 presents the results of parameter estimates of model fittings for the specific attrition rate. The fittings gave high correlation coefficient of determination, $\mathrm{R}^{2}$, of 0.999 whereas the standard errors across the parameters were all very low which implies that the exponential decay model adequately describes the specific attrition rate of the catalyst. The $\mathrm{R}^{2}$ value from this work was higher than 0.989 reported in the work of $\mathrm{Wu}$ et al [10]. From the model fitting, the attrition rate on this unit at steady state was found to be $1.08115 \mathrm{~kg}^{2} / \mathrm{hr}$; this could be attributed to the loss due to activities at the bubble phase, particle motion, inter-particle collision and gas flows necessary to keep the bed fluidized in accordance with the works of Thon et al [5] and Werther \& Reppenhagen [8]. The initial specific attrition rate was $-0.00136 \mathrm{~kg}^{2} / \mathrm{hr}$ whereas a total decay of $1.08251 \mathrm{~kg}^{2} / \mathrm{hr}$ was recorded for this unit over the period of operation. Standard Errors of 0.0059 and 0.0061 were obtained for the parameters $R_{c}$ and $D$ respectively. T-values 182.1219 and -176.9888 respectively give the ratio of the sample regression coefficient to the standard error across these parameters. Also, the Standard Error of 0.000908 over the unit indicates the statistical accuracy of the model prediction. RSS value of $1.403 * 10^{-5}$ shows very low discrepancy between the data and the estimation model hence a proof of the extent of its accuracy. Moreover, the percentage error of $7.90 * 10^{-3}$ shows the closeness of the observed and predicted specific attrition values and therefore provides further confirmation of the precision and accuracy of these modeled parameters.

\section{CONCLUSION}

FCC unit operation results in catalyst attrition and this work have successfully predicted the rate of attrition on a commercial grade catalyst used in an industrial FCC operation. The rate of catalyst attrition was evaluated with an existing model, whereas the specific attrition rate has also been determined using both an existing and predicted models. Modeling of the specific attrition rate using the exponential decay model gave $\mathrm{R}^{2}$ value of 0.999 , SE 0.000908 and RSS value of $1.403 * 10^{-5}$. The percentage error between observed and predicted models of the specific attrition rates was $7.90 * 10^{-3}$.These results give further evidences of catalyst attrition on this unit. It also shows that these models adequately predicted the rate of attrition of the catalyst.

\section{ACKNOWLEDGMENT}

The authors acknowledge the World Bank Africa Centre of Excellence for Oilfield Chemicals Research, University of Port Harcourt-Nigeria for their support in carrying out this research. 


\section{REFERENCES}

[1] Wu, D. F., Gu, Z. D., Li, Y. D. (2015). Attrition of catalyst particles in a laboratory-scale fluidized bed reactor. Chem Eng Sci. 2015: 135: 431-440.

[2] Wei, J., Lee, W., Krambeck, F.J. (1977). Catalyst Attrition and deactivation in Fluid Catalytic Cracking system, J. Chemical Engineering Science, 32: 1211 - 1218.

[3] Kramp, M., Thon, A., Hartge, E.-U., Heinrich, S., Werther, J. (2011). The Role of Attrition and Solids Recovery in a Chemical Looping Combustion Process, Oil \& Gas Science and Technology Rev. IFP Energies nouvelles, 66 (2): 277-290.

[4] Werther, J., Hartge, E. U. (2003). Modelling of Fluidized Bed Reactors, International Journal of Chemical Reactor Engineering, 9: 1-47.

[5] Thon, A., Kramp, M., Hartge, E., Heinrich, S., Werther (2013). Catalyst attrition in the CFB riser, $10^{\text {th }}$ International Conference on Circulating Fluidized Beds and Fluidization Technology - CFB-10", T. Knowlton, PSRI Eds, ECI Symposium Series, (2013). http://dc.engconfintl.org/cfb10/78.

[6] Hartge, E.U., Heinrich, S., Werther, J., Puttmann, A., Thon, A., Patience, G., Bockrath, R. (2010). Prediction of catalyst attrition in an industrial Fluidized bed plant based on lab scale attrition tests, refereed proceedings the $13^{\text {th }}$ International Conference on Fluidization - New Paradigm in Fluidization Engineering, 1-8.

[7] Tamjid, S., Hashemabadi, S.H., Shirvani, M. (2010). Fluid catalytic cracking: Prediction of catalyst attrition in a regeneration cyclone, Filtration+Separation September/October 2010, pg 29 - 33.

[8] Werther, J. and Reppenhagen, J. (1999). Catalyst Attrition in Fluidized-Bed Systems, AIChE J., 45(9): 2001- 2010.

[9] Püttmann, A., Hartge, Werther, J. (2006). E. U., simulation of the selective oxidation of n-butane to maleicanhydride in a riser/regenerator system, www.researchgate.net/publication/268287351.

[10] Wu, D., Wu, F., Li, Y. (2016). Particle Size Effect on the Catalyst Attrition in a Lab-Scale Fluidized Bed, AIChE Journal, DOI 10.1002/aic. 15458

[11] Chiranjeevi, T., Ravichander, N., Gokak, D.T., Ravikumar, V., Choudary, N.V. (2014). The Selection of Fluid Catalytic Cracking Catalysts and Additives: The Significance of Attrition Studies, J.Petroleum Science and Technology, 32:470-478.

[12] Wu, J. S., Li, X. G., Gong, M. Y., Zhang, Z. H., Guo, J. T. (2010). Kinetics and mechanism of several FCC catalysts. $J$ Chinese Soc Corros Protect, 30(2):135-140.

[13] Meyer, A.J., Angwafor, J., Prytz, A.K., Tveten, E., Dyrøy, A. (2018).The Effect of Alumina Attrition Index on Breakage in Transport and Handling,Travaux 47, Proceedings of the 36th International ICSOBA Conference, Belem, Brazil, 29 October - 1 November, 2018.

[14] Fiske, T.H. (2013). Correlation of Catalyst Morphology with Attrition Resistance and Catalytic Activity of Fischer Tropsch Catalysts, Thesis submitted to Department of Chemical Engineering, Norwegian University of Science and Technology (unpublished)

[15] Vogt, E. T. C., Weckhuysen, B. M. (2015). Fluid catalytic cracking: recent developments on the grand old lady of zeolite catalysis, J.Chem. Soc. Rev, 44: 7342-7370.

[16] Gamero, P. M., Maldonado, C. M., Moreno, J.C. M., Guzman, O. M., Mojica, E. M., Gonzalez, R. S. (1997). Stability of an FCC catalyst matrix for processing gas oil with resid, J. Studies in surface science and catalysis, 375-382.

[17] Al-Khattaf, S. (2003). The Influence of Alumina on the Performance of FCC Catalysts during Hydrotreated VGO Catalytic Cracking, Energy Fuels, 17 (1): 62-68.

[18] Sadeghbeigi, R. (2000). Fluid Catalytic Cracking Handbook Design, Operation and Troubleshouting of FCC facilities. Gulf Professional Publishing, Houston, 2, 234-275. 